\title{
Influence of a Thermal Treatment on the Tensile Strength and Equilibrium Moisture Content of Bamboo (Guadua angustifolia Kunth)
}

\author{
Ricardo Acosta, ${ }^{\mathrm{a}, *}$ Jorge A. Montoya, ${ }^{\mathrm{b}}$ and Goran Schmidt ${ }^{\mathrm{c}}$ \\ Thermal treatments applied to lignocellulosic materials were found to \\ induce internal chemical reactions, which modified the physical and \\ mechanical properties and dimensional stability of the material. A 3-year- \\ old basal section of bamboo (Guadua angustifolia Kunth), with no nodes \\ and no skin, was subjected to a thermal treatment at temperatures which \\ ranged from 160 to $200{ }^{\circ} \mathrm{C}$ for 1 to $4 \mathrm{~h}$. The tensile stiffness showed a \\ slight increase with temperature and time, while the tensile strength \\ showed a notable increase at $160{ }^{\circ} \mathrm{C}$ for $2 \mathrm{~h}$. There was a $5 \%$ difference \\ in the equilibrium moisture content at $80 \%$ relative humidity between the \\ untreated samples and the $200^{\circ} \mathrm{C}, 4 \mathrm{~h}$ treatment.
}

Keywords: Bamboo; Guadua angustifolia Kunth; Tension test; Moisture sorption analysis; Physical properties; Mechanical properties; Thermal treatment

Contact information: a: School of Technology, Technological University of Pereira, Pereira, Colombia; $b$ : School of Environmental Sciences, Technological University of Pereira, Pereira, Colombia; c: Institute of Wood Research, Thuenen Institute, Hamburg, Germany; *Corresponding author: ricosta@utp.edu.co

\section{INTRODUCTION}

Thermal treatments (TT) can be defined as the application of heat to wood to achieve the desired performance improvement (Hill 2006). Thermal treatments induce internal chemical reactions and can be used to change the color, reduce the hygroscopicity (EMC), and increase the dimensional stability. The color change is considered as an aesthetic aspect and is considered a correlating indicator for the intensity of thermal modification as well. However, the major loss of mass at higher temperatures is seen as a problem (Nguyen et al. 2012; Bremer et al. 2013). Moreover, TT weakens the mechanical performance of wood (Sandberg and Navi 2007) and thus limits its application range.

A similar challenge for bamboo is the weakening of strength properties (Leithoff and Peek 2001) and its brittle behavior after TT. Thermal treatment in common temperature ranges can decrease the strength by $30 \%$, reduce density by up to $20 \%$, and increase the fragility of the material (Majano 2014). Many bamboo species have been investigated for their mechanical behavior after thermal modification. Investigations were done for commercial species from Vietnam (Nguyen et al. 2012), Ethiopia (Starke et al. 2016), Brazil (Colla et al. 2011), China (Zhang 2013), and Colombia (Archila et al. 2014). Colla et al. (2011) treated Asian Dendrocalamus giganteus in inert and non-inert atmospheres for several hours, resulting in improved thickness swelling and stable mechanical properties. Yun et al. (2016) investigated Chinese moso Phyllostachys pubescens bamboo and explained the mechanical weakness with changes in crystallinity of bamboo cellulose. Zhang et al. (2013) showed the negative effects on mechanical properties for the same Asian bamboo species. Starke et al. (2016) used nitrogen as treatment medium and 
recommended temperature for African highland bamboo Yushania alpina treatment from 140 to $220{ }^{\circ} \mathrm{C}$. Comparable results were presented by Schmidt et al. (2020, 2016). Archila et al. (2014) thermally treated Guadua angustifolia but also combined it with a severe densification for use in panel products. The sole effect of thermal treatment on mechanical properties, especially tensile strength for the Colombian Guadua angustifolia, has not been well studied yet.

Moreover, the extent of property change depends on process temperature, process gas, time, and whether a closed or open system is applied (Tjeerdsma et al. 2002). Thermal treatments can be performed via either pyrolysis or hydrolysis processes. For the pyrolysis process, the wood must be dried previously, the systems are open and are maintained at atmospheric pressure with high temperatures; the cycles are long-running, generate emissions, and consume a lot of energy. For the hydrolysis process, the wood does not need to be dried previously, the systems are closed and are subjected to high pressures and relatively low temperatures. The material is heated up close to the pyrolysis temperature an inert environment to prevent combustion. Then the temperature remains constant for a certain time (treatment time) and a controlled cooling is carried out for conditioning the modified material. Hence, the cycles are short, and the emissions generated and total energy consumption are both lower than pyrolysis (Klaas 2019). A possible drawback might be a higher brittleness and variability in closed systems, as shown for eucalypt wood (Wentzel et al. 2019).

Velásquez et al. (2005) used the basal section of bamboo, with no nodes and without thermal treatment, according to ISO TC-165 INBAR (1999) and measured a MOR value of 190.7 MPa. González et al. (2006) used the basal section of bamboo, with no nodes and without thermal treatment, and at $65 \% \mathrm{RH}, 20{ }^{\circ} \mathrm{C}$, and a moisture content (MC) of $12 \%$, had a MOR value of 191.6 MPa and a MOE value of $17139.2 \mathrm{MPa}$ for the basal section. This test was done following the recommendations of standards ISO 22157-1 (2004) and ISO 22157-2 (2004). Takeuchi (2014) used the basal section of bamboo, with no nodes and without thermal treatment, and at $65 \% \mathrm{RH}, 20{ }^{\circ} \mathrm{C}$, and a moisture content (MC) of $12 \%$, had a MOE value of $21150 \mathrm{MPa}$. This test was carried out following standards ASTM D143 (2014) and NTC 5525 (2007).

Archila et al. (2014) combined TT at $150{ }^{\circ} \mathrm{C}$ and densification at $6.2 \mathrm{MPa}$, and achieved results of $16210 \mathrm{MPa}, 22800 \mathrm{MPa}$, and $31040 \mathrm{MPa}$ for the MOE values of the untreated sample, the densified dry sample and the densified moist sample respectively. All samples contained nodes and were conditioning beforehand at $70 \% \pm 5 \% \mathrm{RH}$ and a temperature of $27{ }^{\circ} \mathrm{C} \pm 2{ }^{\circ} \mathrm{C}$. This test was carried out following the recommendations established in the standards ISO 22157-1 (2004), ISO 22157-2 (2004), and NTC 5525 (2007).

In this study, bamboo Guadua angustifolia Kunth skinless strips, were thermally treated by hydrolysis in a closed pressurized system with temperatures between 160 to 200 ${ }^{\circ} \mathrm{C}$ and times between 1 to 4 hours. No additional densification was done. The results of MOR, MOE and EMC of the thermally treated bamboo were analyzed.

\section{EXPERIMENTAL}

Three-year-old bamboo (Guadua angustifolia Kunth) was harvested a natural plantation located in the botanical garden of the Technological University of Pereira (Pereira, Colombia). Located at a latitude of 4.791959, a longitude of -75.68896 , a height 
above sea level of $1450 \mathrm{~m}$, an average temperature of $20^{\circ} \mathrm{C}$, and an annual rainfall of 2600 $\mathrm{mm}$. The material was processed according to Fig. 1 . The green bamboo culm was cut into internode sections and marked from bottom up (20, 22, 24, 26, 28, 30, 32, 34, 36, 38, 40, and 42 , basal section) according to each internode. The culms were split into strips, and the skin was removed.

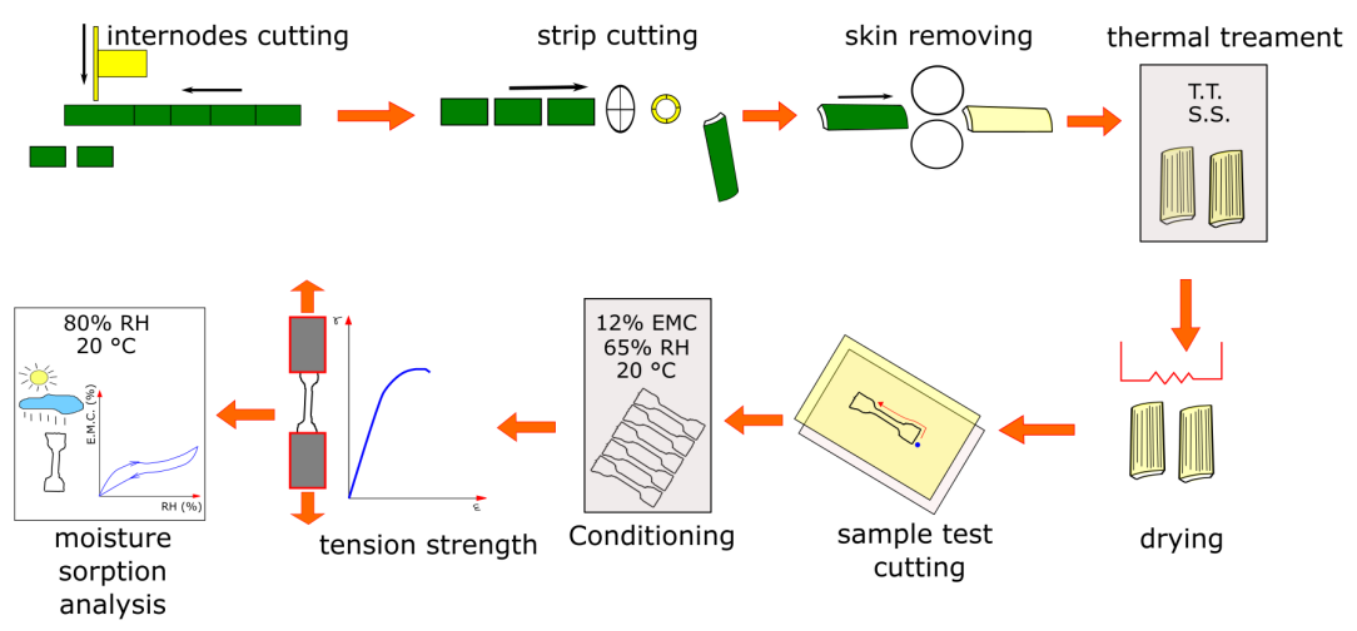

Fig. 1. Experiment methodology

The TT was carried out in a batch reactor of four compartments (Fig. 2), where the processed material is located at the temperature and time indicated (Fig. 3).

The TT preformed in a pressurized, saturated steam (SS) atmosphere (hydrolysis). The SS was obtained by adding a specific amount of water to each of the compartments and sealing them until the end of the process.
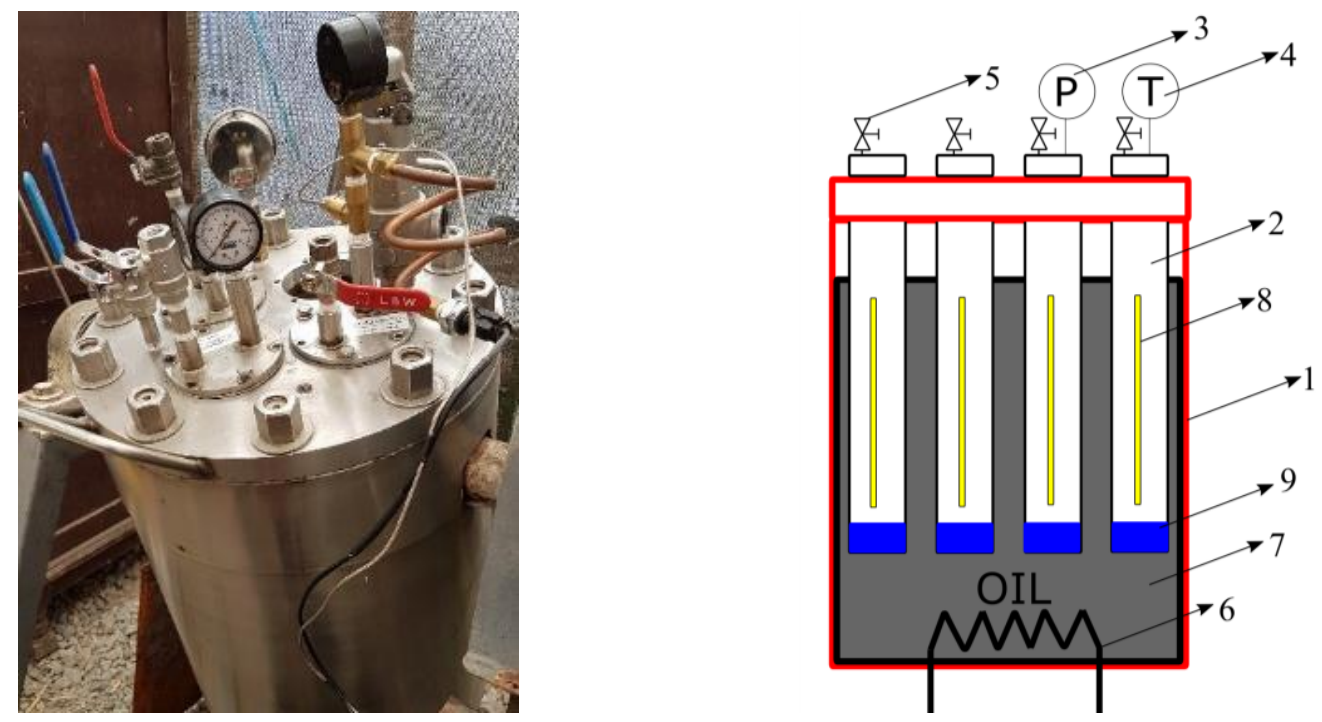

Fig. 2. Four compartment reactor, 1. Main deposit, 2. Compartments, 3. Pressure gauges, 4. Thermocouple, 5. Steam exhaust valves, 6. Electric resistance, 7. Heat fluid, 8. Samples, 9. Water added

The reactor had a main tank (1) containing the heating fluid (7), which was heated by means of an electric resistor (6). This fluid was responsible for heating four 
compartments (2) in which each of the bamboo samples was located and an amount of water was added to generate SS. Once the heat treatment time had elapsed, the respective compartment was depressurized by opening the steam exhaust valves (5). Then, the gates were opened and the samples (8) were withdrawn. The thermocouple (4) sensed the temperature and interacted with the control system to sustain the temperature. Pressure gauges (3) allowed to measure the pressure in each of the compartments (2).

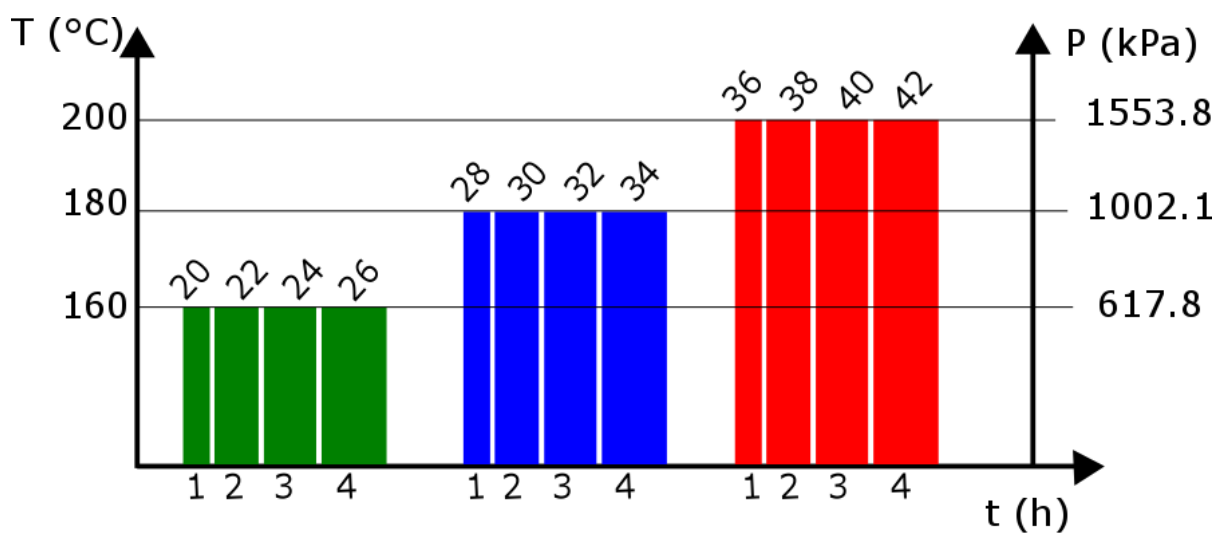

Fig. 3 . Thermal treatment program number, culm section, temperature, and time

At the end of each TT, the steam exhaust valve was activated, the compartment was opened, and the samples were removed. The samples were left outdoors until they reached ambient temperature and then dried in an oven at $103{ }^{\circ} \mathrm{C} \pm 2{ }^{\circ} \mathrm{C}$ for $24 \mathrm{~h}$, before being sanded and sized with a bench router, sample template, and milling cutter.

Figure 4 illustrated the final dimensions, as follows: width (a) $=10 \mathrm{~mm}$, thickness (b) $=5 \mathrm{~mm}$, clamping width $(\mathrm{c})=20 \mathrm{~mm}$, equivalent clamping height $(\mathrm{h})=30 \mathrm{~mm}$, total length of the specimen $(\mathrm{l})=140 \mathrm{~mm}$, and radius of curvature $(\mathrm{r})=50 \mathrm{~mm}$.
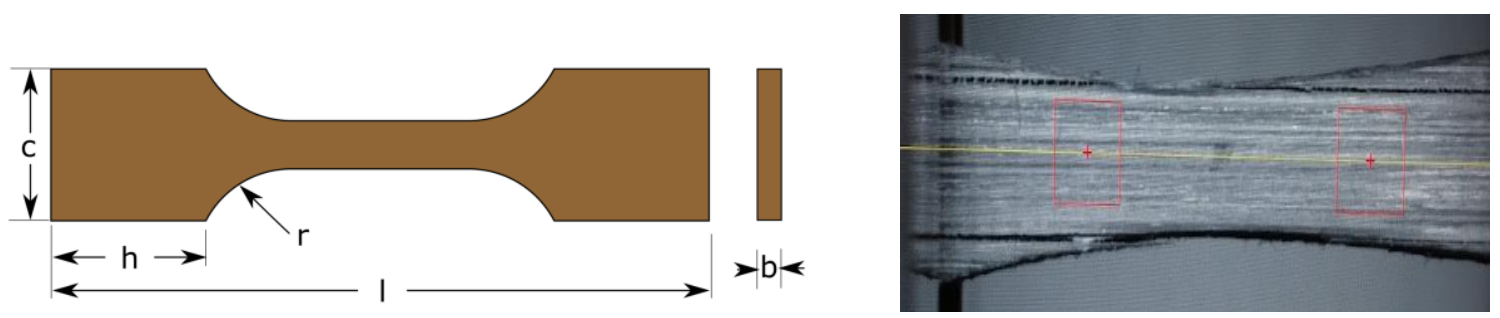

Fig. 4. Measurement of the test specimen and Video extens axial strain

The tension strength test was carried out using a universal testing machine (ZwickRoell Z050, Zwick GmbH \& Co. KG, Ulm, Germany) with fixed grips and a $100 \mathrm{~N}$ preload. Axial strain was measured with a contact-free method using video monitoring (VideoExtens). The actual strain gauge length was set at $40 \mathrm{~mm}$ and the specimen strain was measured continuously until ultimate stress was reached. The configuration of the test was carried out following the recommendations established in the standards ISO 22157-1 (2004) and ISO 22157-2 (2004). Eight specimens were loaded for each treatments. 

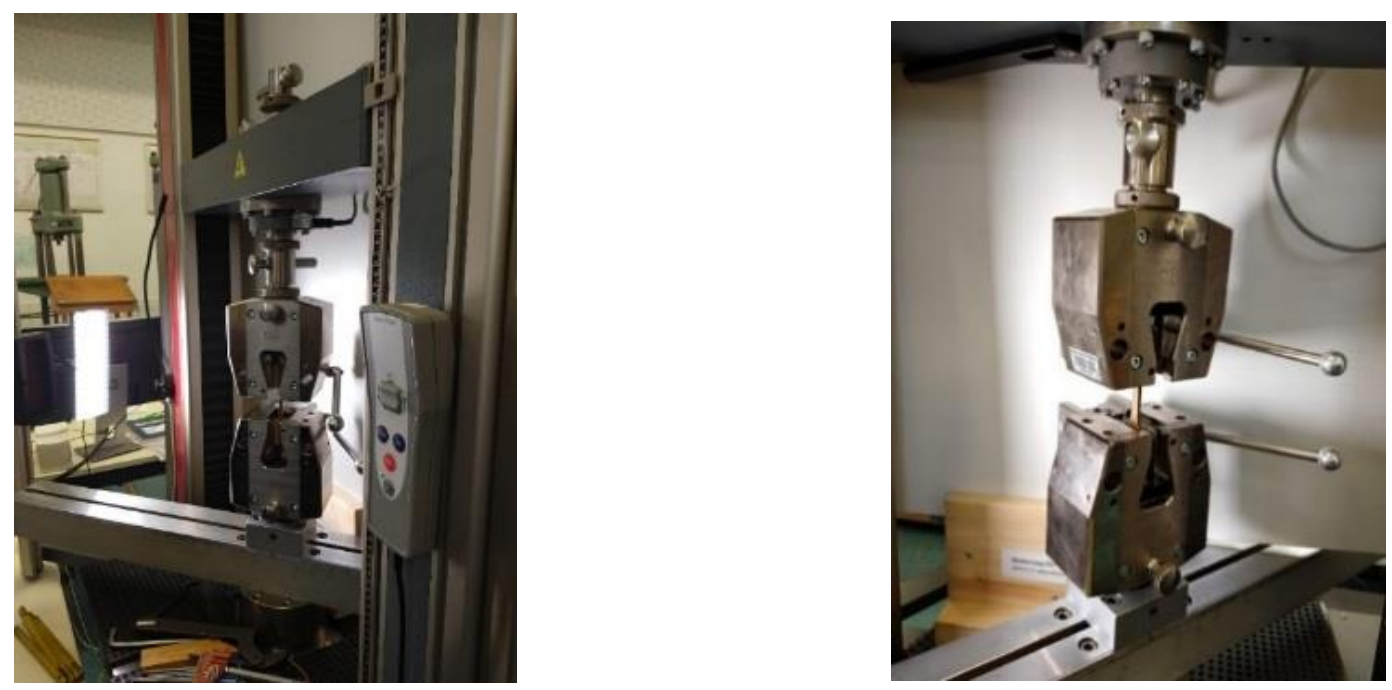

Fig. 5. Universal tension test machine and grips

Flaked bamboo (Fig. 6) was analyzed with a multisample dynamic moisture sorption balance (SPSx-1 $\mu$ Advance, ProUmid GmbH \& Co. KG, Ulm, Germany) following the recommendations established in the standard ASTM D4442-16 (2016). Before performing the tensile strength test and moisture sorption analysis, the samples were subjected to conditioning at $20{ }^{\circ} \mathrm{C}$ and $65 \%$ relative humidity (RH) for $15 \mathrm{~d}$. Moisture sorption analysis was performed once for each thermal treatment.
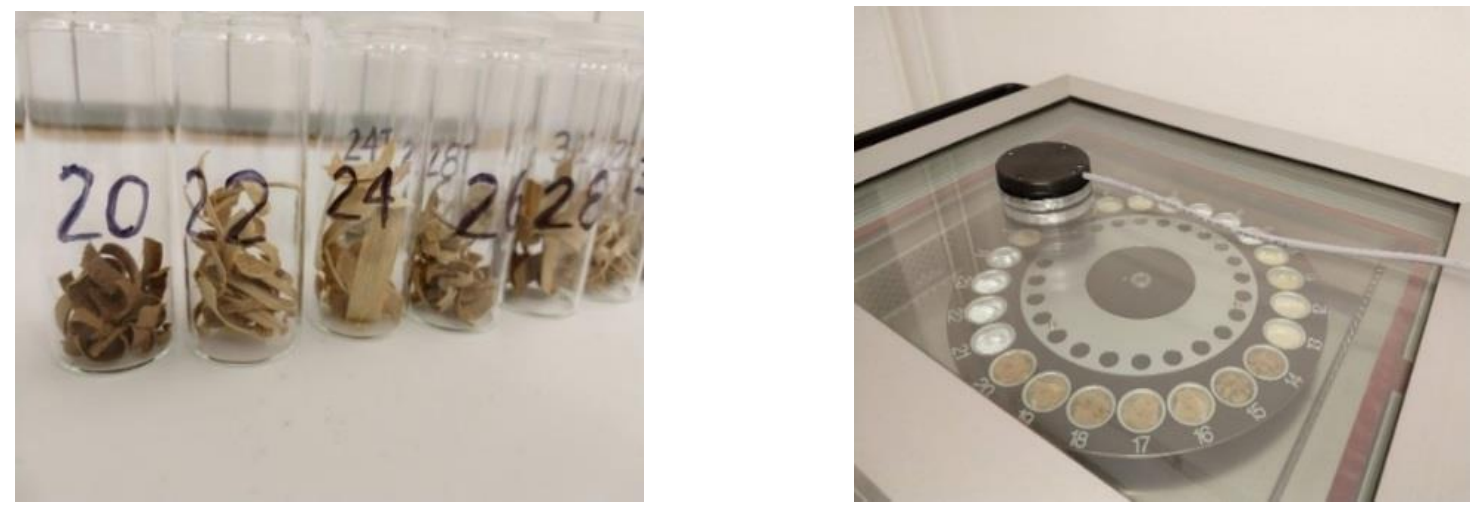

Fig. 6. Flaked bamboo samples and moisture sorption analysis equipment

\section{RESULTS AND DISCUSSION}

The mechanical and physical properties, modulus of elasticity (MOE), modulus of rupture (MOR) and EMC, were dependent on the thermal treatment, temperature, and time and were interconnected. Table 1 summarized the results for all treatment parameters. The MOR, MOE, and EMC of the control samples were $191 \mathrm{MPa}, 16960 \mathrm{MPa}$, and 15.0\%, respectively. The EMC at $80 \% \mathrm{RH}$ and $20{ }^{\circ} \mathrm{C}$ showed that there was an approximately $5 \%$ difference between the control samples and the $200{ }^{\circ} \mathrm{C}, 4 \mathrm{~h}$ treatment. This was caused by a modification of the structural polymers, cellulose, hemicellulose, and lignin. This modification is greater in hemicellulose, since it has a greater number of accessible hydroxyl groups (Bremer et al. 2013) and is thermally less stable than lignin and cellulose. 
Table 1. Results of the MOR, MOE, and EMC for the Thermally Treated Bamboo (Guadua angustifolia Kunth)

\begin{tabular}{|c|c|c|c|c|c|c|c|c|c|c|c|}
\hline \multirow[t]{2}{*}{$\begin{array}{l}\text { Inter- } \\
\text { node }\end{array}$} & \multirow[t]{2}{*}{$\begin{array}{c}\mathrm{T} \\
\left({ }^{\circ} \mathrm{C}\right)\end{array}$} & \multirow[t]{2}{*}{$\begin{array}{c}\mathrm{p} \\
(\mathrm{kPa})\end{array}$} & \multirow[t]{2}{*}{$\begin{array}{l}\mathrm{t} \\
\text { (h) }\end{array}$} & \multirow{2}{*}{$\begin{array}{c}\text { Mass } \\
\text { Loss } \\
(\%)\end{array}$} & \multicolumn{3}{|c|}{$\begin{array}{c}\text { MOR } \\
(\mathrm{MPa})\end{array}$} & \multicolumn{3}{|c|}{$\begin{array}{c}\text { MOE } \\
(\mathrm{MPa})\end{array}$} & \multirow{2}{*}{$\begin{array}{c}\text { EMC (\%) at } \\
20{ }^{\circ} \mathrm{C} / 80 \% \\
\mathrm{RH}\end{array}$} \\
\hline & & & & & Mean & $S^{2}$ & $\mathrm{CV}$ & Mean & $\mathrm{S}^{2}$ & $\mathrm{CV}$ & \\
\hline $\begin{array}{c}\text { untrea } \\
\text { ted }\end{array}$ & - & - & - & - & 190.6 & 895.6 & 15.7 & 16982 & 6676754 & 15.2 & 15.0 \\
\hline 20 & 160 & 617.8 & 1 & 18.0 & 234.3 & 2331.0 & 20.6 & 19338 & 15254891 & 20.2 & 12.5 \\
\hline 22 & 160 & 617.8 & 2 & 22.5 & 263.6 & 439.3 & 7,9 & 14795 & 903662 & 6.4 & 13.7 \\
\hline 24 & 160 & 617.8 & 3 & 38.5 & 255.3 & 257.72 & 6.2 & 14957 & 14067640 & 25.0 & 14.2 \\
\hline 26 & 160 & 617.8 & 4 & 44.4 & 270.1 & 126.28 & 4.1 & 17470 & 2896825 & 9.7 & 14.7 \\
\hline 28 & 180 & 1002.1 & 1 & 13.1 & 215.4 & 1193.6 & 16.0 & 17956 & 4492444 & 11.8 & 13.8 \\
\hline 30 & 180 & 1002.1 & 2 & 27.8 & 225.0 & 541.8 & 10.3 & 14792 & 6111199 & 16.7 & 14.0 \\
\hline 32 & 180 & 1002.1 & 3 & 27.4 & 180.7 & 259.17 & 8.9 & 18695 & 9370226 & 16.3 & 13.8 \\
\hline 34 & 180 & 1002.1 & 4 & 30.9 & 203.4 & 1894.1 & 21.4 & 20226 & 10723100 & 16.1 & 13.5 \\
\hline 36 & 200 & 1553.8 & 1 & 15.9 & 177.0 & 834.0 & 16.3 & 16866 & 3136342 & 10.5 & 14.0 \\
\hline 38 & 200 & 1553.8 & 2 & 21.9 & 246.8 & 459.9 & 8.6 & 18225 & 15330739 & 21.4 & 12.7 \\
\hline 40 & 200 & 1553.8 & 3 & 18.7 & 154.7 & 848.0 & 18.8 & 20597 & 283505 & 2.5 & 13.2 \\
\hline 42 & 200 & 1553.8 & 4 & 22.4 & 109.0 & 177.29 & 12.2 & 16296 & 3487459 & 11.4 & 10.7 \\
\hline
\end{tabular}

Figure 7 shows the surface and contour plots for the MOR as a function of temperature and time. A substantial decrease was observed for treatments with a temperature of $180{ }^{\circ} \mathrm{C}$ or higher and a time longer than or equal to $3 \mathrm{~h}$. The MOR increased by $38 \%$ for the thermal treatment at $160^{\circ} \mathrm{C}$ and $2 \mathrm{~h}$ compared to the untreated sample.

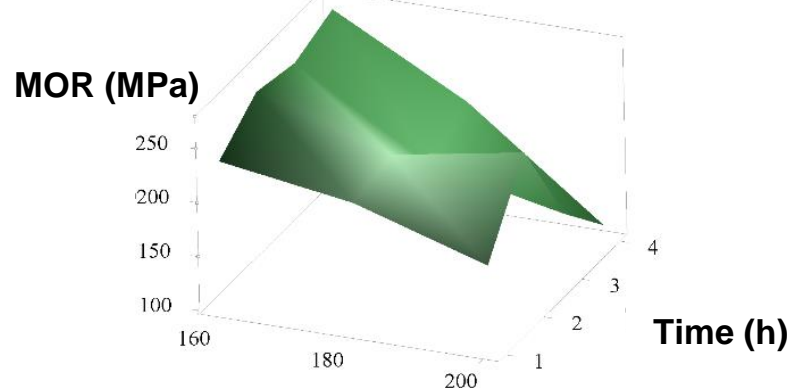

Temperature $\left({ }^{\circ} \mathrm{C}\right)$

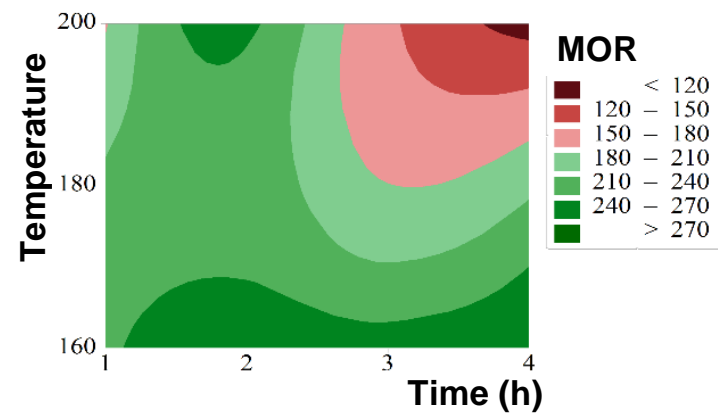

Time (h)

Fig. 7. Surface and contour plot MOR (MPa) vs. $T\left({ }^{\circ} \mathrm{C}\right)$ and $t(\mathrm{~h})$

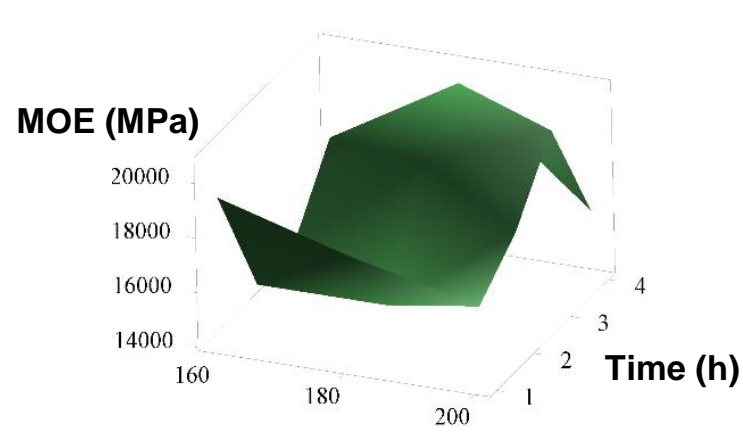

Temperature $\left({ }^{\circ} \mathrm{C}\right)$

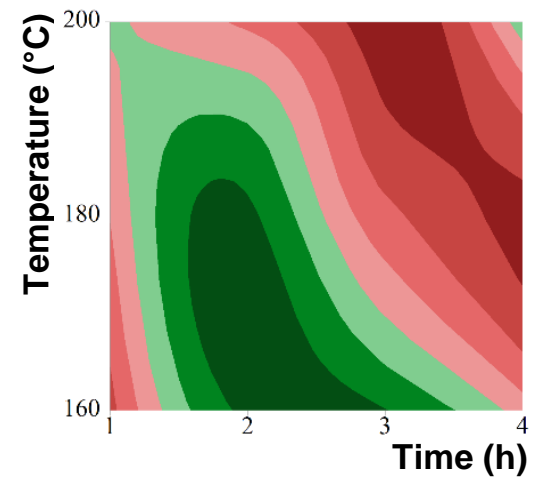

MOE (MPa)

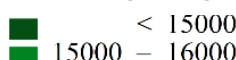

$15000-16000$

$16000-17000$

$17000-18000$

$18000-19000$

$19000-20000$

$>20000$

Fig. 8. Surface and contour plot MOE (MPa) vs. $T\left({ }^{\circ} \mathrm{C}\right)$ and $\underline{t}(\mathrm{~h})$ 
Figure 8 shows the surface and contour graphs of the MOE as a function of temperature and time. There was neither a notable change in the MOE for temperatures from of 160 to $180{ }^{\circ} \mathrm{C}$ and treatment times of 2 to $3 \mathrm{~h}$. The MOE increased at a treatment time greater than $3 \mathrm{~h}$ for 180 to $200{ }^{\circ} \mathrm{C}$ temperatures. This might have been cause by a lower EMC in the treated samples.

EMC showed noticeable decrease at a temperature of $200{ }^{\circ} \mathrm{C}$ and for a time of $4 \mathrm{~h}$. A slight variation was also observed for temperatures between 160 and $180{ }^{\circ} \mathrm{C}$ and a time of 2 to $4 \mathrm{~h}$.
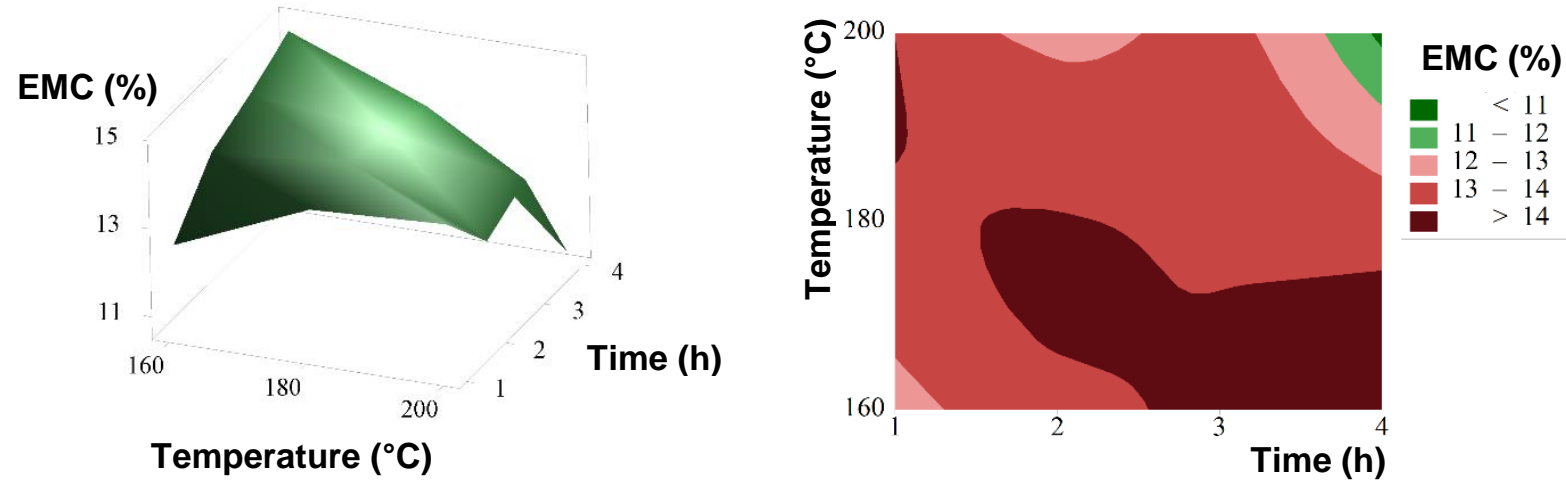

Fig. 9. Surface and contour plot EMC (\%) vs. $T\left({ }^{\circ} \mathrm{C}\right)$ and $t(\mathrm{~h})$

There were no significant differences for the MOR results of untreated samples when compared to González et al. (2006) and Velásquez et al. (2005). There were no significant differences for the MOE results of untreated samples when compared to González et al. (2006) and Archila et al. (2014) and there was a difference of $24.5 \%$ when compared with Takeuchi (2014).

The MOR results obtained by Colla et al. (2011) for $180^{\circ} \mathrm{C}, 10 \mathrm{~h}$ in giant bamboo were lower than the results of the samples treated at $180^{\circ} \mathrm{C}$ and $1,2,3$, and $4 \mathrm{~h}$. This may be mainly due to the difference in the duration of the TT and multiple factors that influenced the results, such as the bamboo species, age, culm section, terrain, and the tensile strength test setup (especially the geometry of the fixation grip clamps).

\section{CONCLUSIONS}

1. The MOR and MOE initially increased and then decreased with treatment temperatures between 160 to $200{ }^{\circ} \mathrm{C}$ and treatment times between 1 to $4 \mathrm{~h}$.

2. The MOE slightly increased with an increase in temperature and time, i.e. that the material became stiffer, while the MOR increased at treatment conditions of $160{ }^{\circ} \mathrm{C}$ and $2 \mathrm{~h}$.

3. The results obtained for the MOR and MOE values after a $200{ }^{\circ} \mathrm{C}$ treatment for $4 \mathrm{~h}$ showed a high degree of variability.

4. In a closed steamed system, thermal treatment substantially decreased the EMC at temperatures above $180^{\circ} \mathrm{C}$.

5. The EMC at $80 \% \mathrm{RH}$ showed that there was an approximately $5 \%$ difference between the untreated samples and the $200{ }^{\circ} \mathrm{C}, 4 \mathrm{~h}$ treatment. 


\section{ACKNOWLEDGMENTS}

The authors are grateful for the support of the Technological University of Pereira, Colombia (Research 9-17-7) and labs of Thünen Institute in Hamburg, Germany.

\section{REFERENCES CITED}

ABNT NBR 13969:1997 (1997). "Septic tanks - Complementary treatment and final disposal plants of liquid effluents - Design, construction and operation," Brazilian Association of Technical Standards, Rio de Janeiro, Brazil.

Archila, S., H. F., Ansell, M. P., and Walker, P. (2014). "Elastic propierties of thermohydro mechanically modified bamboo (Guadua angustifolia Kunth) measured in tension," Key Engineering Materials 600, 111-120. DOI:

10.4028/www.scientific.net/KEM.600.111

ASTM D143-16 (2014). "Standard Test Methods for Small Clear Specimens of TimberStandard" ASTM International, West Conshohocken, PA.

ASTM D4442-16 (2016). "Standard test methods for direct moisture content measurement of wood and wood-base materials," ASTM International, West Conshohocken, PA.

Bremer, M., Fischer, S., Nguyen, T. C., Wagenführ, A., Phuong, L. X., and Dai, V. H. (2013). "Effects of thermal modification on the properties of two Vietnamese bamboo species. Part II: Effects on chemical composition," BioResources 8(1), 981-993. DOI: 10.15376/biores.8.1.981-993

Colla, W. A., Beraldo, A. L., and Brito, J. O. (2011). "Effects of thermal treatment on the physicochemical characteristics of giant bamboo," Cerne 17, 361-367. DOI:

10.1590/S0104-77602011000300010.

Gonzalez, B., H. A., Montoya, J. A., and Bedoya, J. R. (2006). "Stress strain and the influence of the relative humidity of the environment and the height along the stretch in the bamboo species Guadua angustifolia Kunth," Scientia et Technica 3(32), 445450.

Hill, C. A. S. (2006). Wood Modification: Chemical, Thermal and Other Processes, John Wiley \& Sons, Ltd, Hoboken, NJ. DOI: 10.1002/0470021748

ISO/TR 22157-1. (2004). "Bamboo - Determination of physical and mechanical propierties - Part I: Requirements," International Organization for Standardization, Geneva, Switzerland.

ISO/TR 22157-2 (2004). "Bamboo - Determination of physical and mechanical propierties - Part 2: Laboratory manual," International Organization for Standardization, Geneva, Switzerland.

Klaas, P. (n.d.). "Wood treatment technology," (https://wtt.global/wpcontent/uploads/2018/01/ThermoTreat-2.0_Product-Presentation.pdf) ) Accessed 12 Nov 2019.

Leithoff, H., and Peek, R. (2001). "Heat treatment of bamboo," International Research Group Wood Preservation, Section 4-Processes, N IRG/WP 01-40216.

Majano, M. A. (2014). Madera Termo-Tratada de Frondosas para uso Estructural [Thermo-treated Hardwood for Structural Use], Ph.D. Dissertation, Universidad Politécnica de Madrid, Madrid, Spain. 
Sandberg, D., and Navi, P. (2007). Introduction to Thermo-hydro-mechanical (THM) Wood Processing (Report No. 30), Växjö University, Växjö, Sweden.

Starke, R. M., Rosenthal, M., Bues, C., Bremer, M., and Fischer, S. (2016). "Thermal modification of African alpine bamboo," European Journal of Wood and Wood Products 74, 901-903.

Schmidt, G., Girma, K., Belda, M., Berthold, D., and Ressel, J. B. (2016). “Technical feasibility report - Bamboo scrimber Ethiopia: Phase I+II," Universität Hamburg and Fraunhofer WKI. Hamburg/Braunschweig. 98p. DOI: 10.13140/RG.2.2.34768.20484

Schmidt, G., Stute, T., Lenz, M. T., Melcher, E., and Ressel, J. B. (2020). "Fungal deterioration of a novel scrimber composite made from industrially heat treated African highland bamboo," Industrial Crops and Products 147, 112225.

Takeuchi, C. P. (2014). Caracterización Mecánica del Bambú Guadua Laminado para uso Estructural [Mechanical Characterization of Guadua Laminated Bamboo], Ph.D. Dissertation, Universidad Nacional de Colombia, Bogata, Colombia.

Velásquez, H. J. C., Saraz, J. A. O., and Restrepo, J. M. V. (2005). "Determination of the tensile and shear mechanical resistance of Guadua angustifolia Kunth," Revista Facultad Nacional de Agronomía Medellín 58(1), 2709-2715.

Wentzel, M., Fleckenstein, M., Hofmann, T., and Militz, H. (2019). "Relation of chemical and mechanical properties of Eucalyptus nitens wood thermally modified in open and closed systems," Wood Material Science \& Engineering 14(3), 165-173. DOI: 10.1080/17480272.2018.1450783

Yun, H., Li, K., Tu, D., Hu, C., and City, G. (2016). "Effect of heat treatment on bamboo fiber morphology crystallinity and mechanical," Wood Research 61(2), 227-234.

Zhang, Y., Yu, W., and Zhang, Y. (2013). "Effect of steam heating on the color and chemical properties of Neosinocalamus affinis bamboo," Journal of Wood Chemistry and Technology 33(4), 235-246. DOI: 10.1080/02773813.2013.779714

Article submitted: September 26, 2019; Peer review completed: January 23, 2020;

Revised version received and accepted: March 10, 2020; Published: March 18, 2020.

DOI: 10.15376/biores.15.2.3103-3111 